\title{
Activated Sludge Acclimation for toluene and DEHP degradation in a Two-Phase Partitioning Bioreactor
}

\section{Biodegradation of volatile organic compounds by activated sludge}

\author{
I. Béchohra ${ }^{\mathrm{a}, \mathrm{b}}$, JB. Le Menn ${ }^{\mathrm{a}, \mathrm{b}}$, A. Couvert ${ }^{\mathrm{a}, \mathrm{b}}, \mathrm{A}$. Amrane $^{\mathrm{a}, \mathrm{b}, \mathrm{c}}$
}

${ }^{a}$ Ecole Nationale Supérieure de chimie de Rennes, CNRS, UMR 6226, 11, Allée de

Beaulieu, CS 50837, 35708 Rennes Cedex 7, France.

${ }^{b}$ Université Européenne de Bretagne, 5 Boulevard Laennec, Rennes, France.

${ }^{c}$ Université de Rennes 1, CNRS, UMR 6226, 3 rue du Clos-Courtel, BP 90433, 35704 Rennes

Cedex 7, France

imane.bechohra@hotmail.fr, jb.lemenn@gmail.com,annabelle.couvert@ensc-rennes.fr,

abdeltif.amrane@ensc-rennes.fr.

*Corresponding author: ENSCR, Equipe CIP, UMR CNRS 6226 ISCR, 11 allée de Beaulieu, CS 50837, 35708 Rennes Cedex 7, France. Tel: 3322323 81 55, Fax: 33223238120 ; Email: imane.bechohra@hotmail.fr

\begin{abstract}
The effect of activated sludge acclimation on the biodegradation of toluene in the presence of a biodegradable Non-Aqueous Phase Liquid (NAPL), di (2-ethylhexyl) phthalate (DEHP), in a two-phase partitioning bioreactor was characterized. The influence of the presence of DEHP, at a ratio of $0.1 \%$ (volume ratio), and of the acclimation of activated sludge on the biodegradation of hydrophobic VOC was studied. Activated sludge was acclimated to both toluene and DEHP simultaneously. Using acclimated cells, $73 \%$ and $96 \%$ improvement of the mean biodegradation rates were recorded for toluene and the organic solvent (DEHP) respectively, if compared to the values recorded in the absence of acclimation, during tests performed in Erlenmeyer flasks. Degradation rates were further improved by the use of acclimated activated sludge (AS) in a reactor with a large head space; degradation yields for toluene and DEHP were above $99 \%$ and $89 \%$ respectively.
\end{abstract}

Keywords: Toluene; DEHP; activated sludge; biodegradation; acclimation. 


\section{Introduction}

The removal of volatile organic compounds (VOCs) from contaminated airstreams has become a major public concern (Malhautier et al. 2014). They are produced by a variety of industries and their emissions are facing increasingly stringent environmental regulations because they affect public health and welfare owing to their toxicity, potential carcinogenicity and stability (Spigno et al. 2003). Biological techniques have attracted considerable interest in recent years because they offer a number of advantages when compared to other traditional air pollution technologies, such as combustion, oxidation, etc (Smith 1991).

However, despite their inherent advantages, the performance of biological gas treatment processes is often challenged by the hydrophobicity of some specific VOCs (such as toluene, benzene), which limits pollutant transfer from the gaseous phase to the aqueous phase containing the microorganisms responsible of pollutants biodegradation (Collins and Daugulis 1999; Arriaga et al. 2006; Hernández et al. 2010; Muñoz et al. 2012). The process limitation in conventional biotechnologies arises from microbial inhibition or $\mathrm{O}_{2}$ limitation during the treatment of high concentrations of water soluble or moderately soluble VOCs, especially during episodes of load surges (Collins and Daugulis 1999; Muñoz et al. 2015).

Two-phase partitioning bioreactors (TPPBs), which are based on the addition to the biological process of solid or liquid non-aqueous phases (NAPL), can enhance the transfer of hydrophobic VOCs, as a result of the high affinity of the organic phase for these latter, as well as that of $\mathrm{O}_{2}$. Therefore, this technology has supported unprecedentedly high elimination capacities (EC) and at the same time decreases target compounds toxicity towards microorganisms by lowering their concentration in the aqueous phase (Van Groenestijn and Lake 1999; Tomei et al. 2010). For instance, some authors reported, for $\alpha$-pinene, elimination capacities at steady state 10 to 12 times higher than those recorded in a similar system without any liquid NAPL (Hernández et al. 2011).

To avoid costly NAPL, such as silicone oils and ionic liquids, which showed to be relevant for implementation in a TPPB (Darracq et al. 2010a; Quijano et al. 2011b; Dumont et al. 2011; Quijano et al. 2011a), but should be recycled owing to their cost, another alternative is to consider an industrial waste containing an organic phase (Chikh et al. 2011; Béchohra et al. 2014). A biodegradable solvent (hexadecane) was used for this purpose as a model solvent. In this case, the solvent should be biodegradable leading to its removal, concomitantly with the target VOC.

This work deals with the implementation of DEHP (Di (2-ethylhexyl) phthalate) in a TPPB, found to be efficient for both the absorption capacity step and at the biodegradation level, since it is biocompatible, non-soluble in 
water and biodegradable (Madsen et al. 1999; Feng et al. 2002; Chao and Cheng 2007; Béchohra et al. 2015). The hydrophobic targeted VOC is toluene, often encountered in gaseous effluents of pulp and paper factories, composting facilities, food industries or other industries (Rappert and Müller 2005; Jin et al. 2007; Darracq et al. 2010b).

The impact of the ratio DEHP/water on the biodegradation performances was previously examined, showing an optimum of $0.1 \%$ (volume ratio) for simultaneous degradation of DEHP and toluene (Béchohra et al. 2015). Indeed, on the one hand, the NAPL quantity must be sufficient to allow a good VOC mass transfer from the organic phase to the aqueous phase, and on the other hand, a too high NAPL amount can be toxic for microorganisms.

The objective of this paper was to characterize the effect of activated sludge acclimation on the biodegradation of toluene and DEHP in the optimal conditions, namely a DEHP to water volume ratio of $0.1 \%$ in the TPPB. Kinetics of the VOC removal was also examined. Considering that both NAPL and VOC can be toxic for microorganisms, preliminary tests were carried out regarding the interest of an acclimation to both compounds; then, the performances reached with activated sludge acclimated to each VOC in the presence of DEHP were compared with those obtained with non-acclimated activated sludge.

\section{Materials and methods}

VOC and Solvent

The selected VOC was toluene from Carbo Erba reagenti and the solvent used was DEHP (MW = $390.60{\mathrm{~g} \cdot \mathrm{mol}^{-}}^{-}$ ${ }^{1}, \mathrm{~d}=0.970, \mathrm{~T}_{\text {boiling }}=-50{ }^{\circ} \mathrm{C}$ ) from Acros organic.

\section{Microorganisms}

The biomass used in this work was activated sludge (AS) from Beaurade, the municipal wastewater treatment plant of Rennes (France) and were maintained in a lab-reactor (Chikh et al. 2011; Béchohra et al. 2014).

DEHP biodegradability 
Biodegradability was measured using BOD OxyTop (WTW, Alès, France). AS from a wastewater treatment plant was used to inoculate samples, which consisted in various volume fractions of DEHP in water, 0.1, 0.5, 2 and 5\%, a blank and the control solution. The initial microbial concentration of dry weight was 0.05 g.L $\mathrm{L}^{-1}$. The following mineral basis was used for all experiments $\left(\mathrm{g} . \mathrm{L}^{-1}\right)$ : $\mathrm{MgSO}_{4} \cdot 7 \mathrm{H}_{2} \mathrm{O}, 22.5 ; \mathrm{CaCl}_{2}, 27.5 ; \mathrm{FeCl}_{3}, 0.15 ; \mathrm{NH}_{4}$ $\mathrm{Cl}, 2.0 ; \mathrm{Na}_{2} \mathrm{HPO}_{4}, 6.80 ; \mathrm{KH}_{2} \mathrm{PO}_{4}, 2.80$ and $\mathrm{N}$-allylthiourea, $10 \mathrm{mg} . \mathrm{L}^{-1}$. The $\mathrm{BOD}_{5}$ value was initially estimated based on the COD value experimentally measured by means of a Nanocolor Test (Macherey-Nagel, Düren, Germany), according to $\mathrm{BOD}_{5}=\mathrm{COD} / 1.46$. The range of expected $\mathrm{BOD}_{5}$ measurement was then deduced and hence led to the volumes of sample, of AS solution.

A similar protocol was applied for the control flask except that except that the content has been replaced by a solution of easily biodegradable compounds, namely glutamic acid $\left(150 \mathrm{mg} . \mathrm{L}^{-1}\right)$ and glucose $\left(150 \mathrm{mg} . \mathrm{L}^{-1}\right)$. Before use, $\mathrm{NaOH}$ was added to achieve neutral $\mathrm{pH}(7.0 \pm 0.2)$. Finally, a similar protocol was also considered for the blank solution, for which the sample was replaced by water to have a negligible BOD $_{5}$ value (Darracq et al. 2010a; Ferrag-Siagh et al. 2013).

Batch and reactor cultures

Experiments were conducted in $250 \mathrm{~mL}$ Erlenmeyer flasks closed with cellulosic caps for the low concentration of toluene $\left(4.3 \mathrm{mg} . \mathrm{L}^{-1}\right)$ to allow air exchange during the first set of experiments. For the high concentration of toluene (106 mg. $\left.\mathrm{L}^{-1}\right)$, glass caps were used. Erlenmeyer are equipped with two sampling points sealed with Teflon septum allowing needle introduction. To sample the gaseous phase, a micro syringe with a capacity of $500 \mu \mathrm{L}$ was used and the sample was injected directly in the gaseous chromatography (GC); aqueous samples could be stored in closed vials for further analysis of by-products. The Erlenmeyer headspace was $50 \mathrm{~mL}$. For each experiment, a given number of identical $250 \mathrm{~mL}$ Erlenmeyer flasks were considered. Initially, concentrations of 4.3 and $106 \mathrm{~g}$ of toluene per liter of DEHP at $0.1 \%$ volume fraction were considered. Each series of experiments consisted of 13 flasks containing 0.5 g.L $\mathrm{L}^{-1}$ of activated sludge and nutrients. A blank test containing the considered amount of DEHP was also carried out to determine the fraction of VOC lost by possible leaks or adsorption on the cellulosic stoppers; its composition was the same as the other flasks except for nutrients and biomass. Stirring was set at $300 \mathrm{rpm}$ and flasks were placed in a thermostated oven $\left(\mathrm{T}=25^{\circ} \mathrm{C}\right)$. Because of the biodegradability and the negligible solubility of DEHP in the aqueous phase, it was not possible to perform a homogenous sampling of the two-phase system and hence a sacrificial method was considered, at pre-determined time intervals, duplicate Erlenmeyers were taken for analysis. Gaseous samples were analyzed to 
quantify the remaining toluene quantity (Béchohra et al. 2015).

Experiments in a semi-batch reactor (closed for the liquid phase but open for the gas phase) of 2 liters were performed with the same organic solvent $(0.1 \%)$ and different toluene concentrations in the DEHP (43. 106 and $212 \mathrm{~g}$ of toluene / L of DEHP). Stirring was set at $300 \mathrm{rpm}$ in a thermostated bath $\left(\mathrm{T}=25^{\circ} \mathrm{C}\right)$. A blank test without AS was carried out for each concentration to quantify the leakage toluene.

The amounts of toluene in the gas phase, $\mathrm{pH}$ and the suspended solid quantity were followed. The sampling of the aqueous phase was also carried out to monitor by-products; the formed $\mathrm{CO}_{2}$ was also monitored and quantified by a Infrared Fourier Transform (FTIR) brand Environment SA spectrophotometer (Cosma reference Beryl 100).

Acclimation of activated sludge to toluene and DEHP

Activated sludge acclimation to VOC and NAPL was performed as follows: a washed solution of AS was put into a closed $1 \mathrm{~L}$ reactor; a Trinci solution at $50 \mathrm{ml} . \mathrm{L}^{-1}$ (Trinci 1969), nitrogen in the form of $\mathrm{NH}_{4} \mathrm{Cl}$ and phosphorus in the form of $\mathrm{KH}_{2} \mathrm{PO}_{4}$ and $\mathrm{NaH}_{2} \mathrm{PO}_{4}$ were added. Increasing amounts of toluene and organic phase were added, starting with $20 \mu \mathrm{L}$ of toluene and $50 \mu \mathrm{L}$ of DEHP the first week and increasing $20 \mu \mathrm{L}$ of toluene and $50 \mu \mathrm{L}$ of organic phase each week. After each toluene exhaustion, air bubbling was carried out, $\mathrm{pH}(7 \pm$ 0.2). Every week, the culture medium was supplied with $10 \mathrm{~mL}$ of Trinci solution, $190 \mathrm{~mL}$ of water, $5 \mathrm{~mL}$ in nitrogen and $2.5 \mathrm{~mL}$ of phosphate after a bleeding of $200 \mathrm{~mL}$ of the supernatant after decantation.

\section{Analytical Methods}

The toluene concentration in the gas phase was measured by gas chromatography (GC) coupled with a flame ionization detector from Thermo scientific (California, United States). Metabolites formed in the aqueous phase were identified by gas chromatography coupled with mass spectrometry (MS) with headspace (HS) from Perkin Elmer (California, United States). For the quantification of DEHP degradation, an extraction by hexane $(25 \%$ volume ratio) coupled to $10 \mathrm{~min}$ ultrasonication was performed. The extract was then analyzed by gas chromatography coupled with a flame ionization detector from Perkin Elmer (California, United States). The analytical conditions are reported in Table 1.

The total amount of toluene $\mathrm{m}_{\mathrm{t}}$ was then deduced from the mass balance (Equation 1):

$$
\mathrm{m}_{\mathrm{t}}=\mathrm{m}_{\mathrm{tg}}+\mathrm{m}_{\mathrm{te}}
$$


$\mathrm{m}_{\mathrm{tg}}, \mathrm{m}_{\mathrm{te}}$ were the toluene mass in the gaseous and emulsion (DEHP in water) phase at a given time $\mathrm{t}$; $\mathrm{m}_{\mathrm{tL}}$, the toluene leakage, was deduced from the blank test between the initial time and a given time t.

$$
\mathrm{m}_{\mathrm{tL}}=\left(\mathrm{m}_{0 \mathrm{gb}}+\mathrm{m}_{0 \mathrm{eb}}\right)-\left(\mathrm{m}_{\mathrm{tgb}}+\mathrm{m}_{\mathrm{tb}}\right)
$$

$\mathrm{m}_{0 \mathrm{gb}}, \mathrm{m}_{0 \mathrm{eb}}$ were the toluene mass of the blank test in the gaseous phase and the emulsion at initial time $\mathrm{m}_{\mathrm{tgb}}$ and $\mathrm{m}_{\text {teb }}$ were the toluene mass of the blank test at a given time $\mathrm{t}$ in the gaseous phase and the emulsion.

The concentration in the emulsion at a given time $\mathrm{t}$ and in the blank test can be then deduced from the partition coefficient $\mathrm{H}$ for different volume fractions (Béchohra et al. 2015) and from the toluene concentration in the gaseous phase at the given time t (Eq. 3):

$$
\mathrm{C}_{\mathrm{e}}=\mathrm{C}_{\mathrm{G}} / \mathrm{H}
$$

The mineralization rate was determined for reactor tests, with and without acclimation; it is defined as the ratio of total carbon moles of $\mathrm{CO}_{2}$ to the number of moles of carbon consumed or initially introduced with the carbon substrates (Solano-Serena et al. 2001), as represented by equation (4):

$$
\% \text { mineralization }={ }^{n} C_{\mathrm{CO} 2} /{ }_{n C_{X}}
$$

With $\mathrm{nCO}_{2}$, the total amount of $\mathrm{CO}_{2}$-carbon formed and $\mathrm{nCx}$ the total amount of carbon initially introduced.

The biomass growth was quantified by means of turbidimetric measurements at $600 \mathrm{~nm}$ which was related to dry matter (DM) through a calibration curve.

\section{Results and discussion}

DEHP biodegradability

Figure 1 shows DEHP biochemical oxygen demand for the four volume ratios DEHP / water (5\%, $2 \%, 0.5 \%$ and $0.1 \%$ ) with a blank test without carbon source and a control. As expected, a very significant increase of the $\mathrm{BOD}_{5}$ value of the control, a solution of glucose and glutamic acid, can be noted, showing the activity of the used activated sludge; while the $\mathrm{BOD}_{5}$ value of the blank, corresponding to the endogenous respiration of the microorganisms remained low throughout the 5 days experiment $\left(5 \mathrm{mg} \mathrm{O}_{2} \cdot \mathrm{L}^{-1}-\right.$ Table 2$)$. 
An increase over time was observed for the different volume ratios of DEHP; $50 \mathrm{mg} \mathrm{O} \mathrm{O}_{2} \cdot \mathrm{L}^{-1}$ was obtained for 0.1 $\%$ DEHP and $40 \mathrm{mgO}_{2} \cdot \mathrm{L}^{-1}$ for the other ratios. This leads to the conclusion that DEHP is used by sludge as carbon source and therefore it is biodegradable. Several authors have studied the biodegradability of DEHP by bacterial strains (Feng et al. 2002; Chen et al. 2007), but also by mixed crop (Chao and Cheng 2007) and activated sludge (Wang et al. 1996).

$\mathrm{BOD}_{5}$ values were obtained after subtracting the blank values. All values regarding biodegradability are collected in Table 2, showing that after subtracting the endogenous respiration all ratios $\mathrm{BOD}_{5}$ on COD values were above 0.4 , indicating that DEHP was a biodegradable compound.

\section{Biodegradation kinetics}

\section{Erlenmeyer experiments}

Biodegradation tests were carried out with acclimated and non-acclimated activated sludge; time-courses of toluene degradation are shown in Figure 2. Significant losses due to toluene leakages were observed, leading to only $9-10 \%$ degraded, while the rest corresponded to leakages. As previously observed, the use of cellulose caps led to important losses, especially for low DEHP in water ratios (Béchohra et al. 2015). It can also be noticed that after acclimation, losses were somewhat reduced, since the acclimated biomass is adapted to the substrate which is therefore more rapidly consumed and then the stripping is limited (Mozo et al. 2012). To reduced toluene leakages, glass caps were previously shown to be relevant, since losses were reduced by $29 \%$ (Béchohra et al. 2015).

DEHP biodegradation was also examined, showing for both AS a decrease of the DEHP amount in the beginning of the cultures, before reaching a constant value between the $1^{\text {st }}$ and the $4^{\text {th }}$ day for non acclimated AS and between the $1^{\text {st }}$ and the $2^{\text {nd }}$ day for acclimated AS (Figure 3). This stationary state may be due to the presence of by-products detected by GC/MS, including 2-ethylhexanol and 3-méthyl, 3-heptanol. According to the literature, by-products are described as being more toxic than the original molecule (Horn et al. 2004). Beyond this phase, a second step of DEHP degradation was observed, certainly due to acclimation of activated sludge to by-products; until reaching $92.4 \%$ and $98.0 \%$ decrease after seven days for non-acclimated and acclimated AS. Some authors have also observed a complete DEHP degradation for an initial solvent concentration of 0.75 g. $\mathrm{L}^{-1}$ (corresponding to $0.08 \%$ DEHP/water volume ratio) in only forty hours, but using a pure Gordonia sp. (Sarkar et al. 2013). 
Toluene concentration $106 \mathrm{mg} . \mathrm{L}^{-1}$ of emulsion

A concentration of $106 \mathrm{~g}$ of toluene per liter of DEHP, corresponding to $106 \mathrm{mg}$ of toluene per liter of emulsion, was previously tested in order to study the microorganisms' behavior with a such high toluene concentration (Béchohra et al. 2015), but acclimated sludge was not considered; tests were therefore performed considering non-acclimated and AS acclimated to toluene and DEHP.

A lag phase of about 48 hours was observed in the case of non-acclimated activated sludge (Figure 4); then a decrease of the toluene amount until its complete removal (60\% of biodegradation), taking the losses into account. On the other hand, in the case of acclimated sludge no lag phase was observed and total toluene consumption was observed after 24 hours of culture, which is confirmed by its absence in the gas phase, and the final degradation yield was $72.7 \%$; the rest corresponded to the losses.

With non-acclimated AS, there was a significant decrease in the amount of DEHP over time until a final mass of $0.03 \mathrm{~g}$, namely $87 \%$ biodegradation at the end of the experiment (Figure 5). For acclimated sludge, there was an increase of both the degradation rate and the degradation yield, with an almost total removal at the end of culture, $96 \%$. These results are in agreement with microbial growth, which was higher in the case of acclimated activated sludge (not shown).

\section{Reactor experiments}

\section{Initial toluene concentration}

Three toluene initial concentrations, 43, 106, $212 \mathrm{~g}$ of toluene per liter of DEHP were tested in the reactor with a liquid volume of 2 liters and a head-space volume of about $1 \mathrm{~L}$. The toluene concentration monitoring is shown in Figure 6. In order to avoid toluene stripping due to air sparging, bubbling with air was carried out at the beginning of the experiment before closing the reactor and introducing toluene; therefore, microorganisms should use the oxygen trapped in the headspace during the biodegradation process. A decrease in the toluene mass was noticed in the gas phase for the high toluene concentration $\left(212 \mathrm{mg} . \mathrm{L}^{-1}\right.$ of emulsion or $212 \mathrm{~g}$ of toluene per liter of DEHP) until its complete removal after 7 days of culture (degradation rate of $7.41 \mathrm{mg} \cdot \mathrm{L}^{-1} \cdot \mathrm{h}^{-1}$ ); toluene degradation yield was $86 \%$ at the end of the experiment, taking the leakages into account. 
For the lowest toluene concentration $\left(43 \mathrm{mg} \cdot \mathrm{L}^{-1}\right.$ of emulsion), there was a total consumption of toluene (99\%) after 33 hours with a degradation rate of $4.90 \mathrm{mg} \cdot \mathrm{L}^{-1} \cdot \mathrm{h}^{-1}$ (Figure 6). It can be noted that the blank test (test without activated sludge) showed negligible leaks for this toluene concentration.

Figure 6 also shows that the toluene amount decreased until its complete removal after a period of 55 hours. Furthermore, after two days of culture, a toluene degradation by-product was detected in the aqueous phase, methyl phenol, confirming some results reported in the literature (Johnson and Olsen 1997). The mean toluene degradation rate was $2.92 \mathrm{mg} \cdot \mathrm{L}^{-1} \cdot \mathrm{h}^{-1}$ with a final yield of $86 \%$, namely significantly higher than the rate recorded in Erlenmeyer flasks, namely $0.72 \mathrm{mg} \cdot \mathrm{L}^{-1} \cdot \mathrm{h}^{-1}$. A blank test was also performed to quantify leaks and take them into account in the mass balance; they were $13 \%$, namely significantly lower than those observed in Erlenmeyer flasks (40\%).

DEHP Monitoring could not be done, since DEHP sampling was not easy in the reactor; all the content of the reactor would be needed for its quantification. Because of the negligible solubility of DEHP in the aqueous phase, it was not possible to perform a homogeneous sampling of the two-phase system. The dry matter concentration was monitored daily by sampling the aqueous phase; a bacterial growth was then observed (not shown).

DEHP degradation yields for the three toluene concentrations tested are reported in Table 3 , showing that the highest degradation yield was obtained for the toluene concentration of $106 \mathrm{mg} . \mathrm{L}^{-1}$.

\section{Successive batches}

Even in the presence of air bubbling before toluene addition, an oxygen limitation was observed. The most appropriate would be to have a continuous air inlet, but it was not possible owing to toluene leaks by stripping; air was therefore bubbled into the liquid phase after total toluene consumption and before its reinjection. The corresponding test was performed and the results are shown in Figure 7. In the case of non-acclimated AS, the rate of degradation increased after addition of toluene, $7.14 \mathrm{mg} \cdot \mathrm{L}^{-1} \cdot \mathrm{h}^{-1}$ against $3.67 \mathrm{mg} \mathrm{L} \mathrm{L}^{-1} \cdot \mathrm{h}^{-1}$ initially, showing an adaptation of the microorganisms to the pollutant.

For acclimated AS, only 24 hours were needed for microorganisms to completely degrade the toluene present and the mean degradation rate was $5.21 \mathrm{mg} \cdot \mathrm{L}^{-1} \cdot \mathrm{h}^{-1}$, and almost twice $\left(9.09 \mathrm{mg} \cdot \mathrm{L}^{-1} \cdot \mathrm{h}^{-1}\right)$ after toluene reinjection. A total of five toluene reinjections were operated with air bubbling prior to inject toluene, without any significant decrease in the toluene degradation rate. 
The DEHP degradation rate after 7 days (end of the run) was $75 \%$ for non-acclimated AS, which was found to be more important than the yield achieved without air bubbling before toluene reinjection (60\%) (results not shown). Degradation by-products were detected, namely 2-ethylhexanol and 3-methyl-3-heptanol. In the case of acclimated AS, the DEHP degradation yield increased until $89 \%$ at the end of the run (7 days). DEHP metabolites were detected at the end of culture, 2-ethyl hexanal, 3-methyl-3-heptanol and 2-ethylhexanol as it was reported by (Horn et al. 2004), but these latter did not seem to negatively impact toluene or DEHP consumptions by the microorganisms.

Mineralization yields obtained after the degradation of toluene and DEHP by non-acclimated and acclimated activated sludge were $32.3 \%$ and $51.9 \%$ respectively. As expected, it was significantly higher in the case of acclimated activated sludge. Leaks are low and non-mineralized amount corresponded to degradation byproducts such as those identified by GC/MS.

\section{Conclusion}

Biodegradation enhancement after microbial acclimation and in the presence of a biodegradable non-aqueous phase liquid (DEHP) was studied through their impact on the biodegradation yields and rates of carbon sources consumption. Degradation experiments of DEHP and VOCs were performed in Erlenmeyer flasks and in a semicontinuous reactor for a volume ratio of DEHP to water of $0.1 \%$. The experiments realized in batch revealed significant degradation for an optimal toluene concentration of $106 \mathrm{mg} . \mathrm{L}^{-1}$ of emulsion or 106 g.L $\mathrm{L}^{-1}$ of DEHP: 73 and $60 \%$ for toluene for acclimated and non-acclimated AS respectively, 96 and $73 \%$ for DEHP for acclimated and non-acclimated AS respectively. These positive results were confirmed during experiments carried out in a reactor involving acclimated cells: degradation yields were more than $99 \%$ and $89 \%$ for toluene and DEHP, respectively.

\section{Acknowledgements}

The technical support of this research was provided by the National School of Chemistry of Rennes. Appreciation is extended to Mrs Marguerite Lemasle, for her help during the analysis of samples by GC/MS.

\section{References}

Arriaga S, Muñoz R, Hernández S, et al (2006) Gaseous hexane biodegradation by Fusarium solani in two liquid phase packed-bed and stirred-tank bioreactors. Environ Sci Technol 40:2390-2395. 
Béchohra I, Couvert A, Amrane A (2014) Biodegradation of toluene in a two-phase partitioning bioreactor impact of activated sludge acclimation. Environ Technol 35:735-740. doi: $10.1080 / 09593330.2013 .848938$

Béchohra I, Couvert A, Amrane A (2015) Absorption and biodegradation of toluene: Optimization of its initial concentration and the biodegradable non-aqueous phase liquid volume fraction. Int Biodeterior Biodegrad 104:350-355. doi: 10.1016/j.ibiod.2015.07.004

Chao WL, Cheng CY (2007) Effect of introduced phthalate-degrading bacteria on the diversity of indigenous bacterial communities during di-(2-ethylhexyl) phthalate (DEHP) degradation in a soil microcosm. Chemosphere 67:482-488. doi: 10.1016/j.chemosphere.2006.09.048

Chen J, Li X, Li J, et al (2007) Degradation of environmental endocrine disruptor di-2-ethylhexyl phthalate by a newly discovered bacterium, Microbacterium sp. strain CQ0110Y. Appl Microbiol Biotechnol 74:676682. doi: 10.1007/s00253-006-0700-3

Chikh R, Couvert A, Aït Amar H, Amrane A (2011) Toluene biodegradation in a two phase partitioning system-Use of a biodegradable solvent. Environ Prog Sustain Energy 30:303-308. doi: 10.1002/ep.10477

Collins LD, Daugulis AJ (1999) Benzene/toluene/p-xylene degradation. Part I. Solvent selection and toluene degradation in a two-phase partitioning bioreactor. Appl Microbiol Biotechnol 52:354-359.

Darracq G, Couvert A, Couriol C, et al (2010a) Silicone oil: An effective absorbent for the removal of hydrophobic volatile organic compounds. J Chem Technol Biotechnol 85:309-313. doi: $10.1002 /$ jctb. 2331

Darracq G, Couvert A, Couriol C, et al (2010b) Kinetics of toluene and sulfur compounds removal by means of an integrated process involving the coupling of absorption and biodegradation. J Chem Technol Biotechnol 85:1156-1161. doi: 10.1002/jctb.2414

Dumont E, Darracq G, Couvert A, et al (2011) VOC absorption in a countercurrent packed-bed column using water/silicone oil mixtures: Influence of silicone oil volume fraction. Chem Eng J 168:241-248. doi: 10.1016/j.cej.2010.12.073

Feng Z, Kunyan C, Jiamo F, et al (2002) Biodegradability of Di(2-Ethylhexyl) Phthalate by Pseudomonas Fluorescens FS1. Water Air Soil Pollut 140:297-305. doi: 10.1023/A:1020108502776

Ferrag-Siagh F, Fourcade F, Soutrel I, et al (2013) Tetracycline degradation and mineralization by the coupling of an electro-Fenton pretreatment and a biological process. J Chem Technol Biotechnol 88:1380-1386. doi: $10.1002 /$ jctb. 3990

Hernández M, Muñoz R, Daugulis AJ (2011) Biodegradation of VOC mixtures of different hydrophobicities in two-phase partitioning bioreactors containing tailored polymer mixtures. J Chem Technol Biotechnol 86:138-144. doi: 10.1002/jctb.2496

Hernández M, Quijano G, Thalasso F, et al (2010) A comparative study of solid and liquid non-aqueous phases for the biodegradation of hexane in two-phase partitioning bioreactors. Biotechnol Bioeng 106:731740. doi: 10.1002/bit.22748

Horn O, Nalli S, Cooper D, Nicell J (2004) Plasticizer metabolites in the environment. Water Res 38:3693-3698. doi: 10.1016/j.watres.2004.06.012

Jin Y, Veiga MC, Kennes C (2007) Co-treatment of hydrogen sulfide and methanol in a single-stage biotrickling filter under acidic conditions. Chemosphere 68:1186-1193. doi: 10.1016/j.chemosphere.2007.01.069

Johnson GR, Olsen RH (1997) Multiple pathways for toluene degradation in Burkholderia sp. strain JS150. Appl Environ Microbiol 63:4047-4052. 
Madsen PL, Thyme JB, Henriksen K, et al (1999) Kinetics of Di-(2-ethylhexyl)phthalate Mineralization in Sludge-Amended Soil. Environ Sci Technol 33:2601-2606. doi: 10.1021/es981015o

Malhautier L, Quijano G, Avezac M, et al (2014) Kinetic characterization of toluene biodegradation by Rhodococcus erythropolis: Towards a rationale for microflora enhancement in bioreactors devoted to air treatment. Chem Eng J 247:199-204. doi: 10.1016/j.cej.2014.02.099

Mozo I, Lesage G, Yin J, et al (2012) Dynamic modeling of biodegradation and volatilization of hazardous aromatic substances in aerobic bioreactor. Water Res 46:5327-5342. doi: 10.1016/j.watres.2012.07.014

Muñoz R, Daugulis AJ, Hernández M, Quijano G (2012) Recent advances in two-phase partitioning bioreactors for the treatment of volatile organic compounds. Biotechnol Adv 30:1707-1720. doi: 10.1016/j.biotechadv.2012.08.009

Muñoz R, Quijano G, Revah S (2015) Two-phase partitioning bioreactors: towards a new generation of highperformance biological processes for VOC and CH4 abatement. In: Electron. J. Energy Environ. http://repositoriodigital.uct.cl/handle/10925/1652. Accessed 25 May 2015

Quijano G, Couvert A, Amrane A, et al (2011b) Toxicity and biodegradability of ionic liquids: new perspectives towards whole-cell biotechnological applications. Chem Eng J 174:27-32.

Quijano G, Couvert A, Amrane A, et al (2011a) Potential of ionic liquids for VOC absorption and biodegradation in multiphase systems. Chem Eng Sci 66:2707-2712. doi: 10.1016/j.ces.2011.01.047

Rappert S, Müller R (2005) Odor compounds in waste gas emissions from agricultural operations and food industries. Waste Manag 25:887-907. doi: 10.1016/j.wasman.2005.07.008

Sarkar J, Chowdhury PP, Dutta TK (2013) Complete degradation of di-n-octyl phthalate by Gordonia sp. strain Dop5. Chemosphere 90:2571-2577. doi: 10.1016/j.chemosphere.2012.10.101

Smith MR (1991) The biodegradation of aromatic hydrocarbons by bacteria. In: Ratledge C (ed) Physiology of Biodegradative Microorganisms. Springer Netherlands, pp 191-206

Solano-Serena F, Marchal R, Vandecasteele JP (2001) Biodégradabilité de l'essence dans l'environnement: de l'évaluation globale au cas des hydrocarbures récalcitrants. Oil Gas Sci Technol 56:479-498.

Spigno G, Pagella C, Daria Fumi M, et al (2003) VOCs removal from waste gases: gas-phase bioreactor for the abatement of hexane by Aspergillus niger. Chem Eng Sci 58:739-746. doi: 10.1016/S00092509(02)00603-6

Tomei MC, Annesini MC, Rita S, Daugulis AJ (2010) Two-phase partitioning bioreactors operating with polymers applied to the removal of substituted phenols. Environ Sci Technol 44:7254-7259.

Trinci APJ (1969) A kinetic study of the growth of Aspergillus nidulans and other fungi. J Gen Microbiol 57:1124.

Van Groenestijn JW, Lake ME (1999) Elimination of alkanes from off-gases using biotrickling filters containing two liquid phases. Environ Prog 18:151-155. doi: 10.1002/ep.670180310

Wang J, Liu P, Qian Y (1996) Biodegradation of phthalic acid esters by acclimated activated sludge. Environ Int 22:737-741. doi: 10.1016/S0160-4120(96)00065-7 
The authors declare that they have no conflict of interest. 
Table1 Analytical conditions implemented to determine the amount of VOC and organic solvent

\begin{tabular}{|c|c|c|c|c|c|c|c|}
\hline Analyte & Apparatus & Column & Detector & $\begin{array}{l}\mathbf{T}_{\mathbf{i n j}} \\
\left({ }^{\circ} \mathbf{C}\right)\end{array}$ & $\begin{array}{l}\mathbf{T}_{\text {oven }} \\
\left({ }^{\circ} \mathbf{C}\right)\end{array}$ & $\begin{array}{l}\mathbf{T}_{\text {det }} \\
\left({ }^{\circ} \mathbf{C}\right)\end{array}$ & Carrier gas \\
\hline $\begin{array}{l}\text { Toluene in } \\
\text { the gas } \\
\text { phase }\end{array}$ & $\begin{array}{l}\text { Thermo } \\
\text { focus GC }\end{array}$ & $\begin{array}{l}\text { CP-FFAP } \\
\text { CB; } \\
25 \mathrm{~m}^{*} 0.32 \mathrm{~mm}\end{array}$ & FID/Split & 200 & 100 & 250 & $\begin{array}{l}\mathrm{N}_{2}: 3.7 \\
\mathrm{~mL} \cdot \mathrm{min}^{-1}\end{array}$ \\
\hline $\begin{array}{l}\text { Metabolites } \\
\text { in the } \\
\text { aqueous } \\
\text { phase }\end{array}$ & $\begin{array}{l}\text { Perkin } \\
\text { Elmer } \\
\text { Clarus } 500 \\
\text { GC/MS }\end{array}$ & $\begin{array}{l}\text { CP-FFAP } \\
\text { CB; } \\
30 \mathrm{~m}^{*} 0.15 \\
\mathrm{~mm}\end{array}$ & MS/HS & 80 & $40-200$ & & $\begin{array}{l}\text { He }: 1 \\
\text { mL.min }\end{array}$ \\
\hline $\begin{array}{l}\text { DEHP in } \\
\text { hexane }\end{array}$ & $\begin{array}{l}\text { Perkin } \\
\text { Elmer }\end{array}$ & $\begin{array}{l}\text { CP-FFAP } \\
\text { CB; } \\
25 \mathrm{~m} * 0.32 \mathrm{~mm}\end{array}$ & FID/Split & 200 & $\begin{array}{l}160- \\
260\end{array}$ & 250 & $\begin{array}{l}\mathrm{N}_{2}: 1 \\
\mathrm{~mL} \cdot \mathrm{min}^{-1}\end{array}$ \\
\hline
\end{tabular}


Table 2 COD and $\mathrm{BOD}_{5}$ for different volume ratios in DEHP in water $\left(\mathrm{mg} \mathrm{O}_{2} \cdot \mathrm{L}^{-1}\right)$

\begin{tabular}{ccccc}
\hline & $\mathbf{0 . 1 \%}$ & $\mathbf{0 . 5 \%}$ & $\mathbf{2 \%}$ & $\mathbf{5 \%}$ \\
\hline COD $_{\text {sample }}$ & $64.5 \pm 0.5$ & $68 \pm 1$ & $70.5 \pm 0.5$ & $72.5 \pm 7$ \\
BOD $_{5 \text { sample }}$ & $50 \pm 5$ & $40 \pm 5$ & $40 \pm 5$ & $40 \pm 5$ \\
BOD $_{\text {5 Blank }}$ & 5 & 5 & 5 & 5 \\
BOD $_{5 \text { without }}$ & $45 \pm 5$ & $35 \pm 5$ & $35 \pm 5$ & $35 \pm 5$ \\
endogenous respiration & & 0.51 & 0.49 & 0.48 \\
BOD $_{5}$ COD & 0.70 & & & \\
\hline
\end{tabular}


Table 3 DEHP degradation rate for different initial toluene concentrations

\begin{tabular}{cc}
\hline Toluene $\left(\mathbf{m g . L}^{-\mathbf{1}}\right)$ & Degradation yields (\%) \\
\hline 212 & 79 \\
106 & 95 \\
43 & 72 \\
\hline
\end{tabular}


Fig.1 Biological oxygen demand after 5 days $\left(\mathrm{BOD}_{5}\right)$ for various ratios of DEHP in water
day 1
day 2
day 3
day 4
day 5

Fig.2 Time-courses of toluene total amount during biodegradation by non-acclimated and acclimated activated sludge in batch culture. $4.3 \mathrm{~g}$ toluene. $\mathrm{L}^{-1} \mathrm{DEHP}, 0.1 \%$ DEHP (volumic ratio), $\mathrm{pH}=7, \mathrm{~T}=25^{\circ} \mathrm{C}$, stirring speed = $300 \mathrm{rpm}$
Non-acclimated AS
Acclimated AS

Fig.3 Time-course of DEHP amount during biodegradation by non-acclimated and acclimated AS in batch culture. $4.3 \mathrm{~g}$ toluene. $\mathrm{L}^{-1} \mathrm{DEHP}, 0.1 \% \mathrm{DEHP}$ in water, $\mathrm{pH}=7, \mathrm{~T}=25^{\circ} \mathrm{C}$, stirring speed $=300 \mathrm{rpm}$
Non-acclimated AS
Acclimated AS

Fig.4 Time-course of toluene total amount during biodegradation by non-acclimated and acclimated AS in batch culture. $106 \mathrm{~g}$ toluene. $\mathrm{L}^{-1} \mathrm{DEHP}, 0.1 \% \mathrm{DEHP}$ in water, $\mathrm{pH}=7, \mathrm{~T}=25^{\circ} \mathrm{C}$, stirring speed $=300 \mathrm{rpm}$

Non-acclimated AS

Acclimated AS

Fig.5 Time-course of DEHP amount during biodegradation by acclimated and non-acclimated AS in batch culture $106 \mathrm{~g}$ toluene. $\mathrm{L}^{-1} \mathrm{DEHP}, 0.1 \% \mathrm{DEHP}$ in water, $\mathrm{pH}=7, \mathrm{~T}=25^{\circ} \mathrm{C}$, stirring speed $=300 \mathrm{rpm}$

Non-acclimated AS

Acclimated AS

Fig.6 Time-course of the total toluene amount during biodegradation by activated sludge in batch culture for various toluene concentrations, $0.1 \% \mathrm{DEHP}$ in water, $\mathrm{pH}=7, \mathrm{~T}=25^{\circ} \mathrm{C}$, stirring speed $=300 \mathrm{rpm}$
$212 \mathrm{mg} . \mathrm{L}^{-1}$
$106 \mathrm{mg} . \mathrm{L}^{-1}$
$\triangle 43 \mathrm{mg} . \mathrm{L}^{-1}$

Fig.7 Time-course of toluene total amount during biodegradation by non-acclimated and acclimated AS in batch culture. $4.3 \mathrm{~g}$ toluene. $\mathrm{L}^{-1}$ DEHP, $0.1 \%$ DEHP in water, $\mathrm{pH}=7, \mathrm{~T}=25^{\circ} \mathrm{C}$, stirring speed $=300 \mathrm{rpm}$

Non-acclimated AS

$\checkmark$ Acclimated AS 


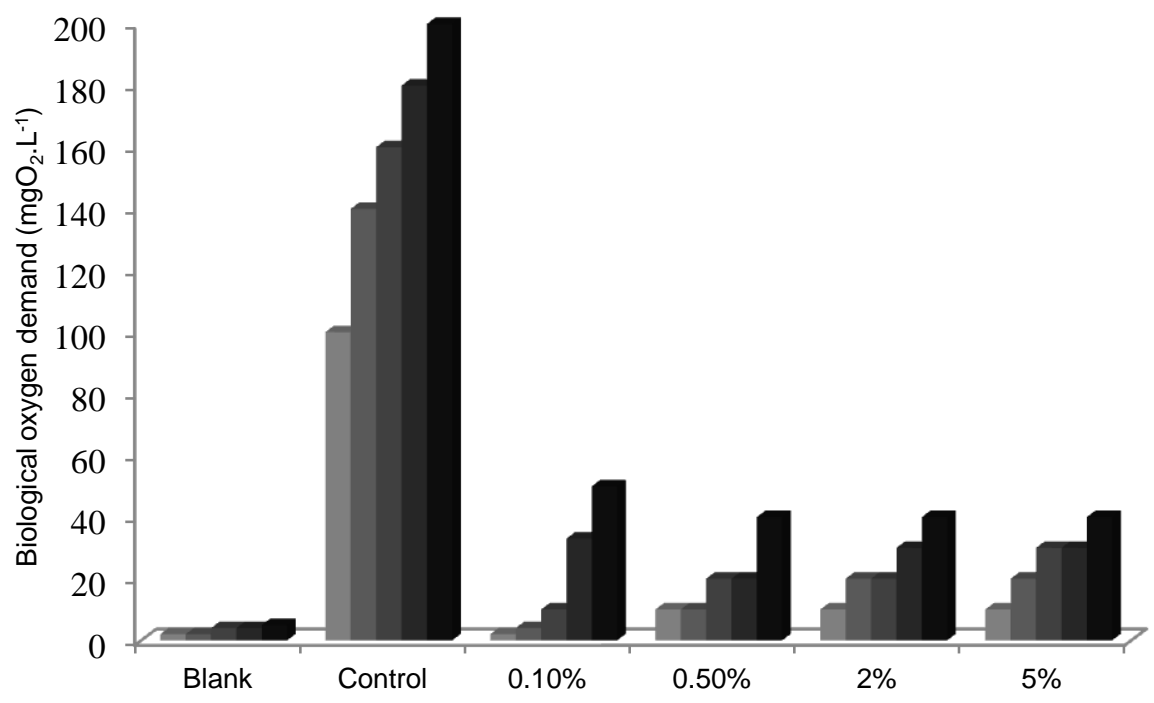




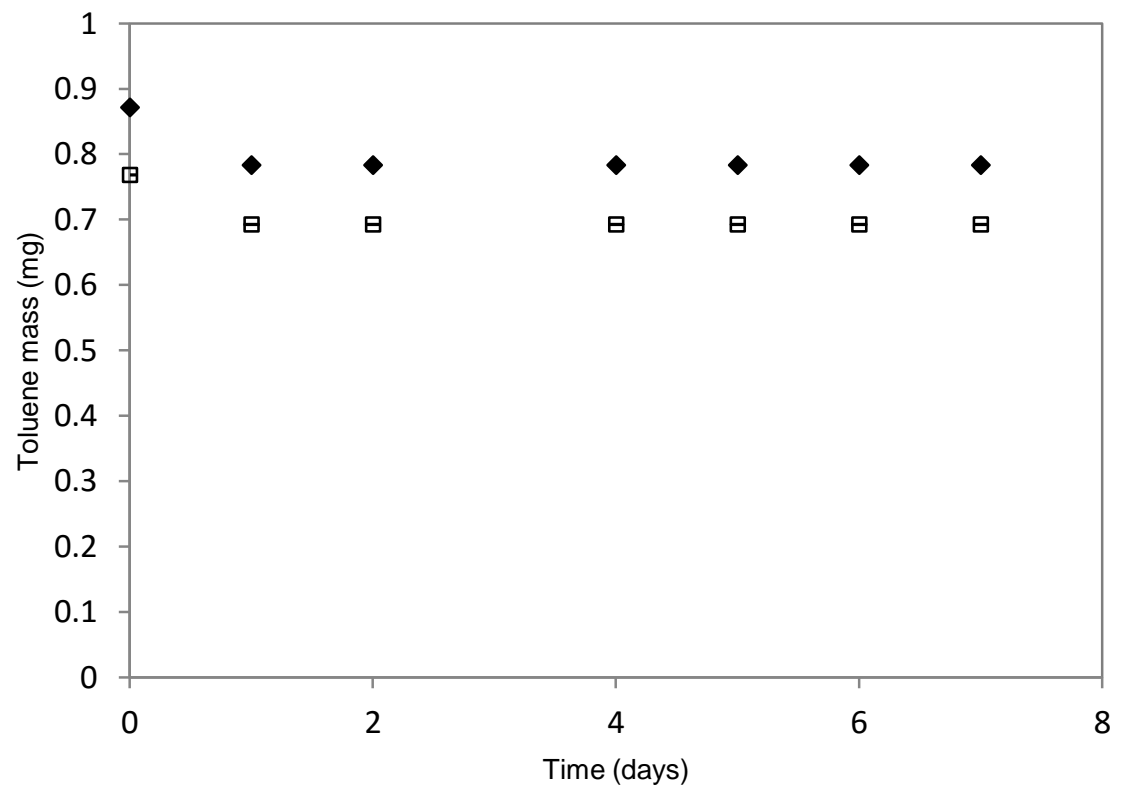




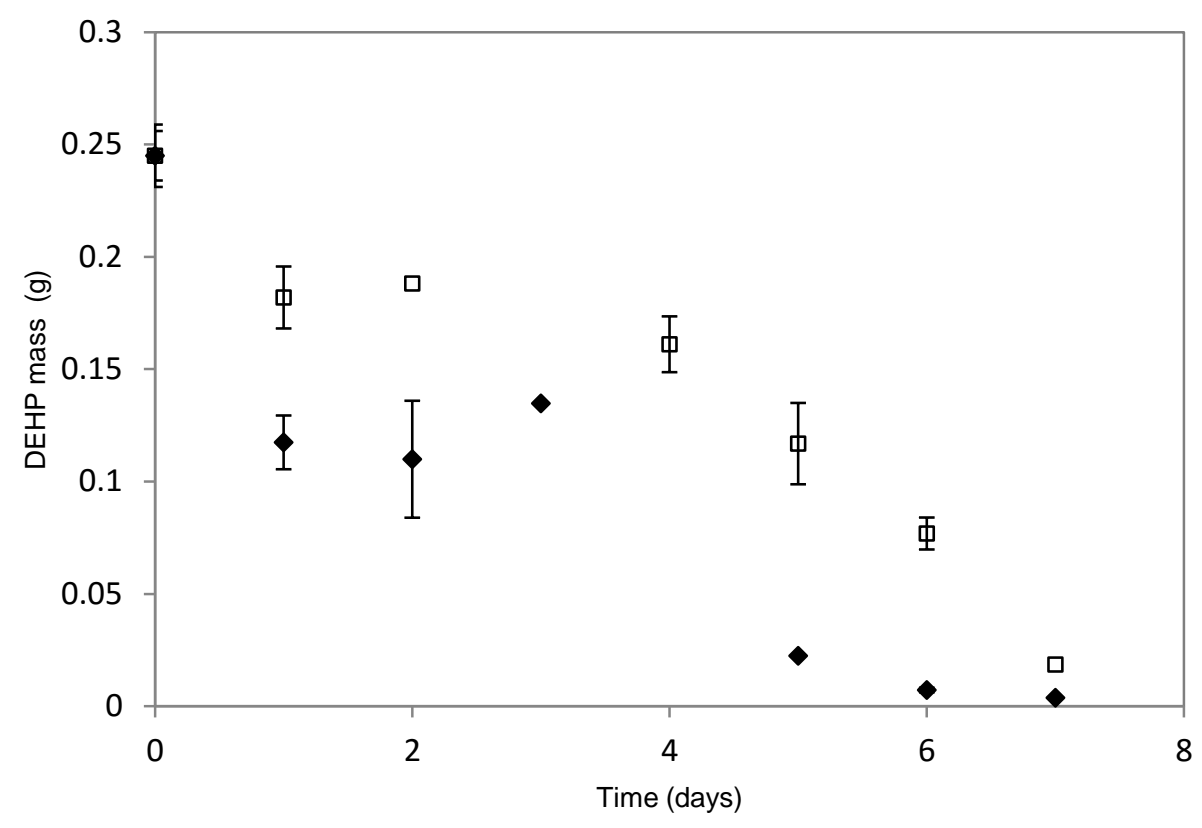




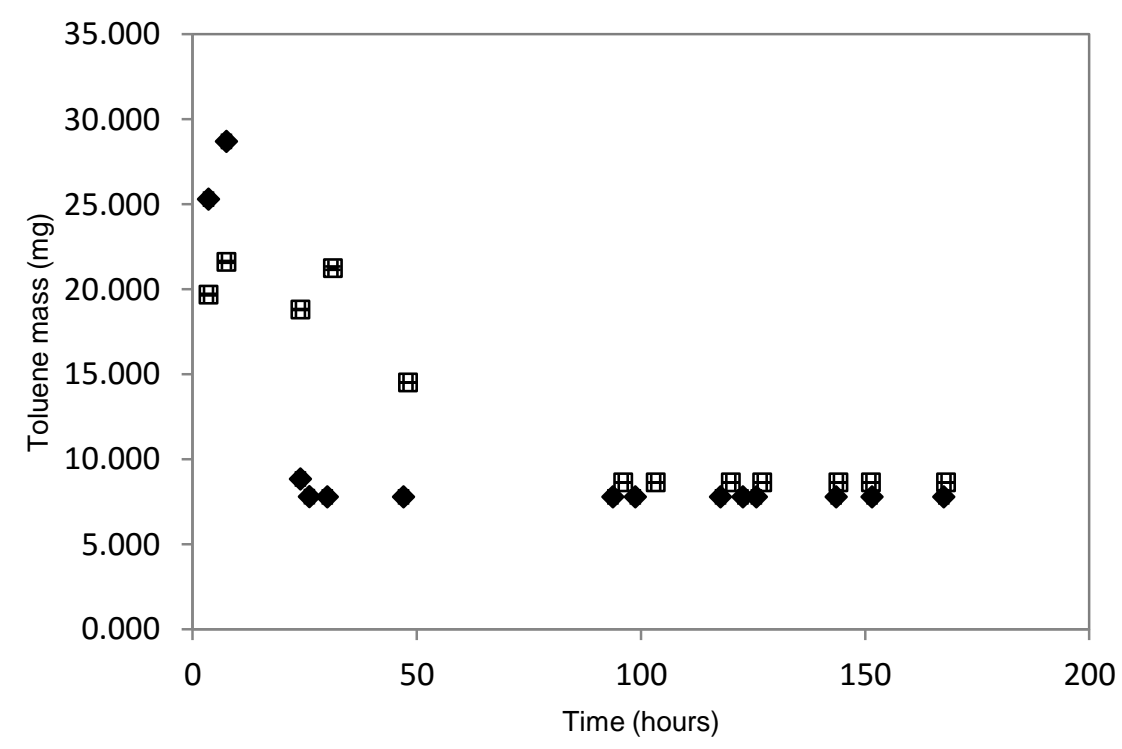




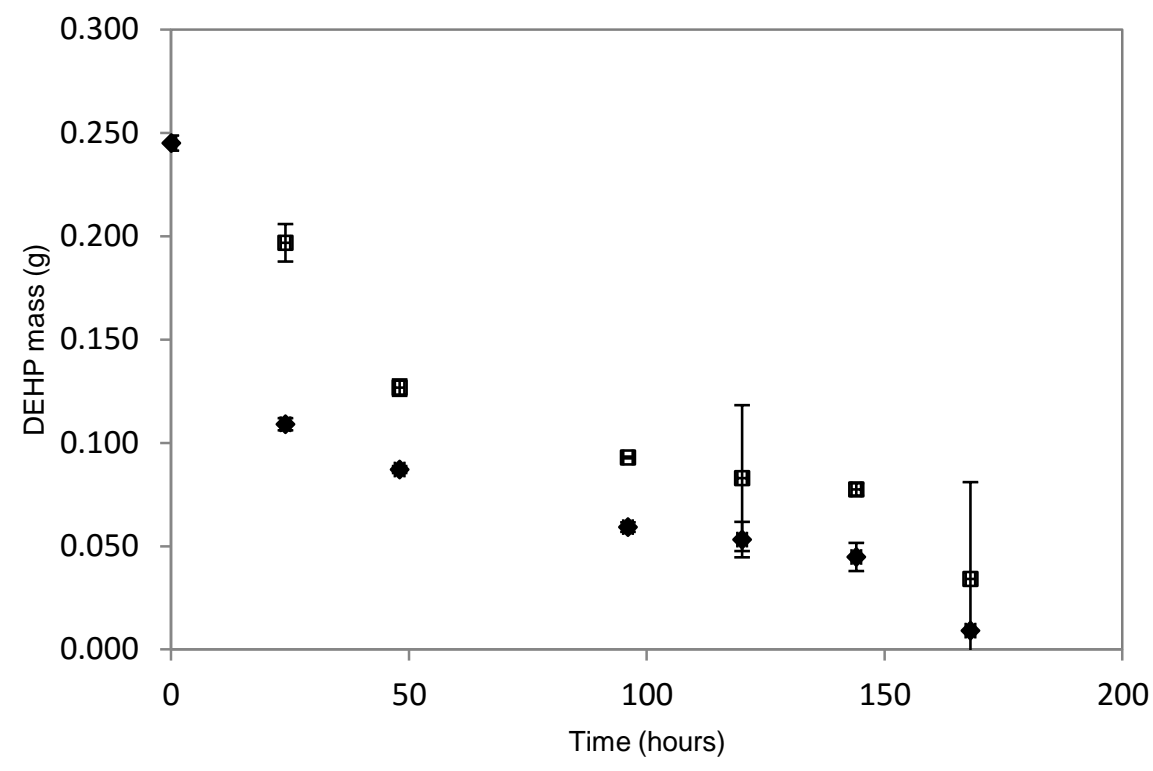




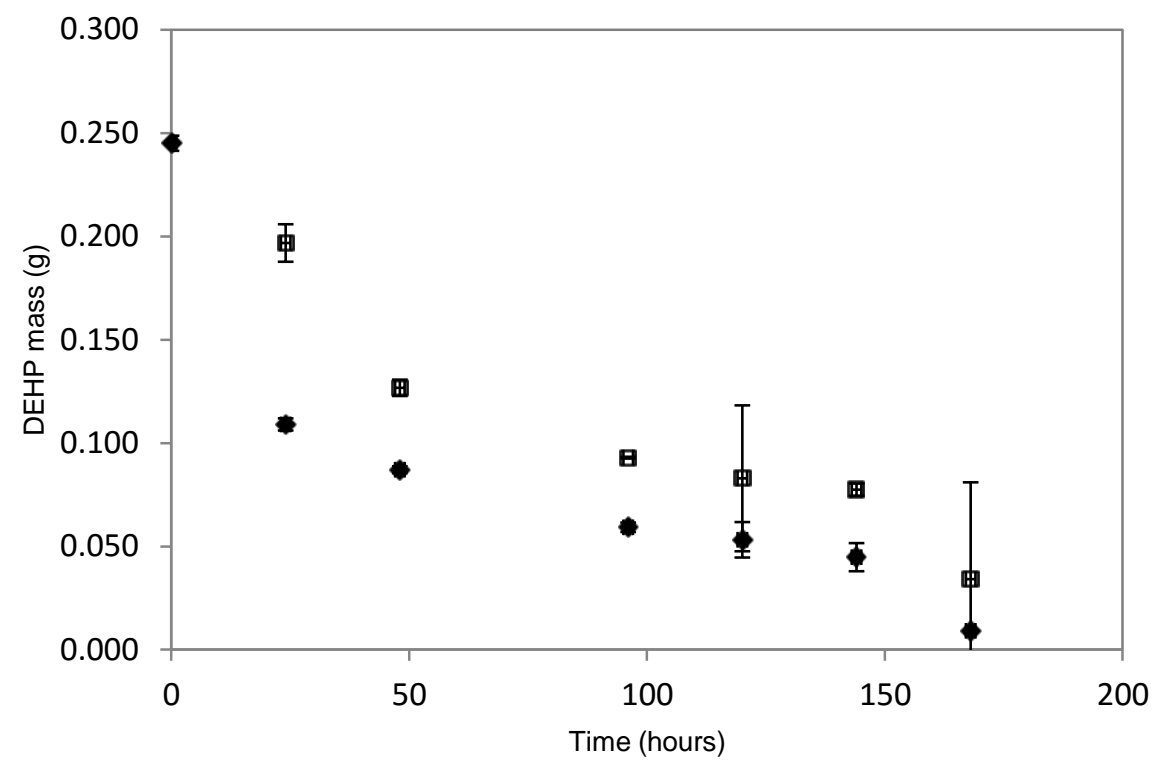



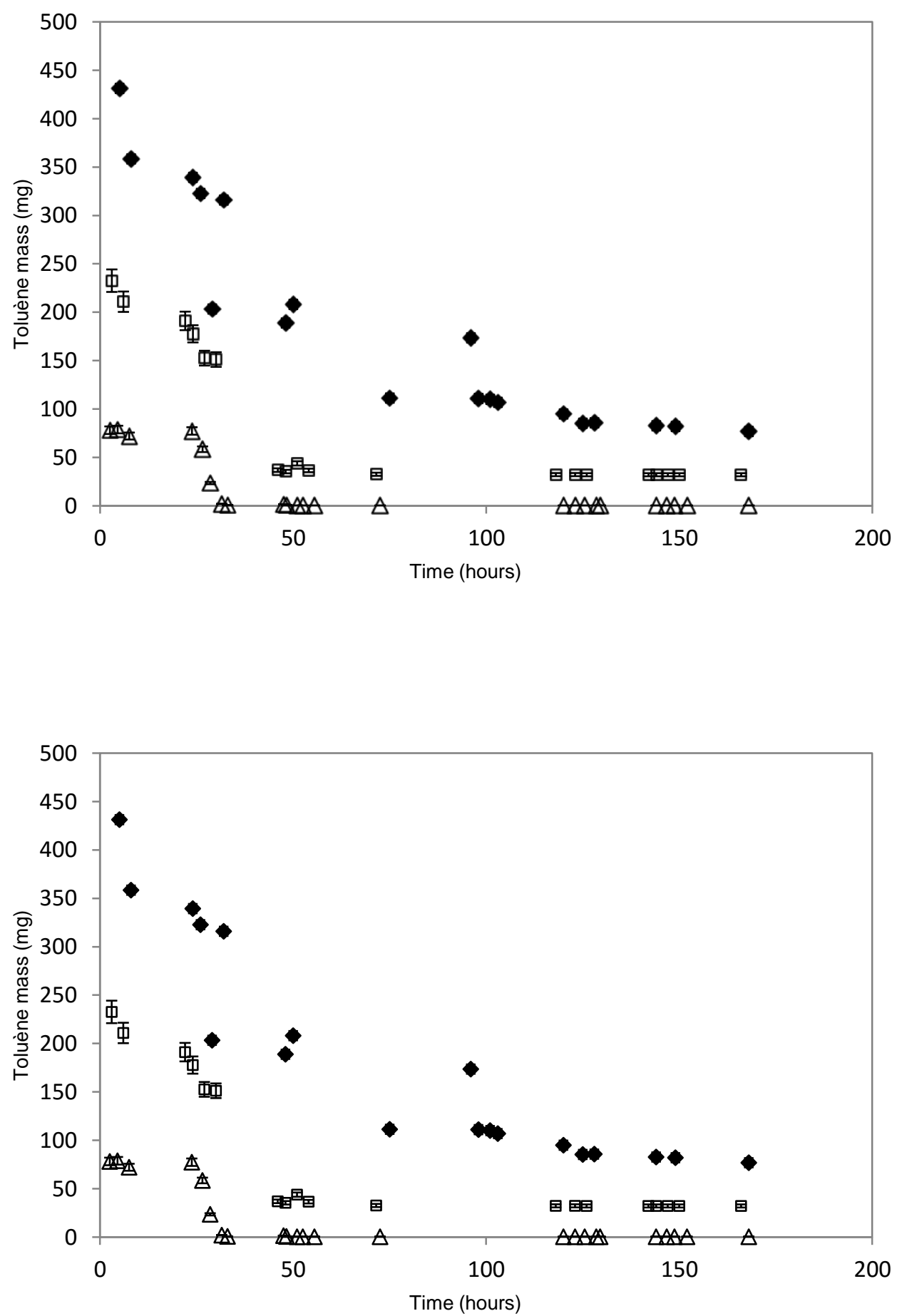


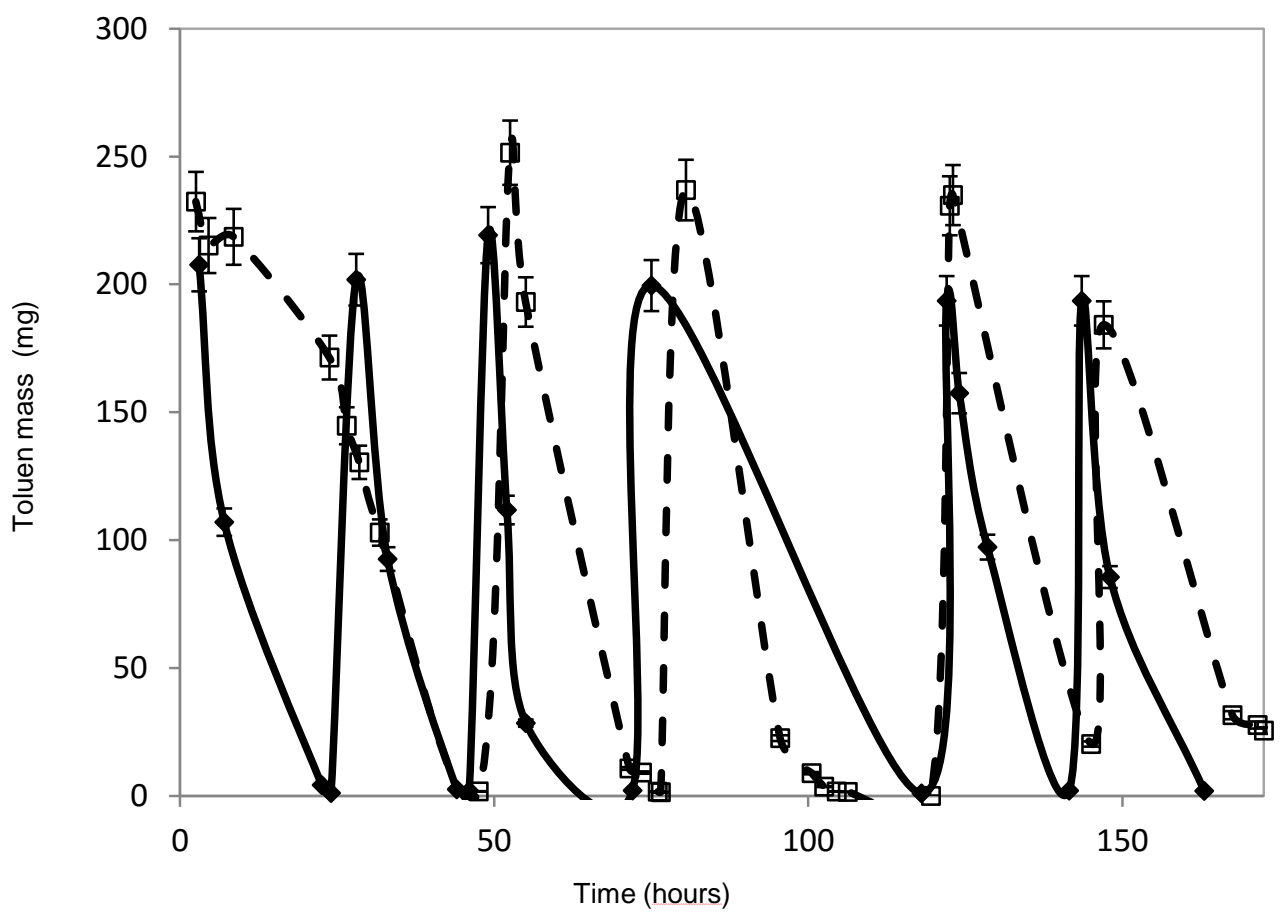

